\title{
Association of hemodynamics during caesarean section, outcomes after caesarean section and hormone changes with different anesthesia in pregnant women with severe pulmonary arterial hypertension
}

\author{
YUN WANG ${ }^{1}$, HAIYAN XU ${ }^{1}$, HAIYAN LI $^{2}$, YAN LIU $^{3}$ and QINGLING BAI ${ }^{4}$ \\ ${ }^{1}$ Department of Obstetrics, Jining First People's Hospital, Jining, Shandong 272000; \\ Departments of ${ }^{2}$ Anesthesiology, ${ }^{3}$ Surgery and ${ }^{4}$ Operation Room, \\ People's Hospital of Zhangqiu District, Jinan, Shandong 250200, P.R. China
}

Received December 19, 2017; Accepted February 16, 2018

DOI: $10.3892 / \mathrm{etm} .2018 .5996$

\begin{abstract}
In the present study we aimed to analyze the effects of different anesthesia methods on the hemodynamics of caesarean section, outcomes after caesarean section and hormone changes in pregnancy complicated with severe pulmonary arterial hypertension (PAH). A total of 75 pregnancy complicated with severe PAH that were treated in Jining First People's Hospital from January 2016 to January 2017 were selected. Three groups were set according to the anesthesia methods, including the subarachnoid combined epidural anesthesia group (group I, $n=25$ ), the epidural anesthesia group (group II, $\mathrm{n}=25$ ) and the general anesthesia group (group III, n=25). Effects on the outcomes of caesarean section of pregnancy complicated with PAH were observed. Sex hormone levels before and 24, 48 and $72 \mathrm{~h}$ after the operation were measured. There were remarkable changes in the postoperative hemodynamics compared with those before anesthesia, but changes in groups I and II were significantly smaller than those in group III $(\mathrm{P}<0.05)$. No significant differences in maternal mortality rate, neonatal mortality rate and neonatal asphyxia rate among the three groups were found $(\mathrm{P}>0.05)$. Time of postoperative mechanical ventilation, ICU residence and hospitalization in groups I and II were shorter than those in group III, the differences were statistically significant $(\mathrm{P}<0.05)$. Postoperative levels of sex hormones, including estradiol (E2), human chorionic gonadotrophin (HCG), prolactin (PRL) and plasma total testosterone (TT) decreased, while postoperative levels of sex hormones follicle
\end{abstract}

Correspondence to: Dr Haiyan Xu, Department of Obstetrics, Jining First People's Hospital, 6 Jiankang, Jining, Shandong 272000, P.R. China

E-mail: cyufi185@163.com

Key words: pregnancy with severe PAH, different anesthesia methods, hemodynamics, outcomes, hormones stimulating hormone (FSH), luteinizing hormone ( $\mathrm{LH})$ and progestogen increased, and differences in the decreased E2 and TT at each time-point were statistically significant $(\mathrm{P}<0.05)$. In conclusion, there is no remarkable difference in the effects of three anesthesia methods on pregnancy outcomes. However, compared with general anesthesia, intravertebral anesthesia achieve shorter time of postoperative mechanical ventilation, ICU residence and hospitalization in pregnancy complicated with severe $\mathrm{PAH}$, which is preferred in pregnancy without contraindication of the anesthesia.

\section{Introduction}

If pulmonary arterial hypertension (PAH) occurs in pregnant women, it will lead to deterioration of hemodynamic status and cardiopulmonary function in the patients (1), with a 3 -year mortality rate at $55 \%$ (2). Termination of pregnancy via caesarean section in intermediate and advanced stage of pregnancy is the major therapeutic method for the disease (3). With the progress in PAH research, some scholars found that in the perioperative period, the sex hormones of the puerperae can regulate the expressions of neurotransmitters and cell receptors, thus influencing the hemodynamics in the body (4). In the present study, the clinical data of 75 pregnant patients complicated with PAH were retrospectively reviewed, and three different anesthesia methods were compared and analyzed, so as to investigate the change rules of sex hormone levels as well as its correlation with hemodynamic changes in PAH patients with pregnancy in the perioperative period and to provide practical bases for selection of appropriate anesthesia methods in clinic.

\section{Patients and methods}

Research objects and grouping. A total of 75 pregnant patients complicated with severe PAH that were admitted and treated in Jining First People's Hospital (Jining, China) from January 2016 to January 2017 were selected and randomly divided into these three groups: The combined spinal/epidural 
Table I. Comparisons of general clinical data among the three groups of puerperae.

\begin{tabular}{lccc}
\hline Items & Group I (n=25) & Group II (n=25) & Group III $(\mathrm{n}=25)$ \\
\hline Age (years) & $28.11 \pm 4.01$ & $27.58 \pm 4.92$ & $27.88 \pm 4.24$ \\
Weight (kg) & $60.22 \pm 3.38$ & $60.77 \pm 3.45$ & $59.58 \pm 4.43$ \\
Gestational age (weeks) & $30.38 \pm 4.98$ & $30.78 \pm 4.02$ & $30.44 \pm 4.35$ \\
Primiparity, n (\%) & $20(80.00)$ & $21(84.00)$ & $19(76.00)$ \\
Cardiac function grading & & & \\
Grade III & $14(56.00)$ & $13(52.00)$ & $14(56.00)$ \\
Grade IV & $10(40.00)$ & $12(48.00)$ & $11(44.00)$ \\
Type of cardiac disease, n (\%) & & & $14(56.00)$ \\
Congenital heart disease & $15(60.00)$ & $13(52.00)$ & $11(44.00)$ \\
Rheumatic heart disease & $10(40.00)$ & $12(48.00)$ & $9(60.00)$ \\
Complication, n (\%) & & & $12(80.00)$ \\
Arrhythmia & $13(52.00)$ & $10(83.33)$ & $7(28.00)$ \\
Hypoproteinemia & $19(76.00)$ & $9(36.00)$ & \\
Pulmonary infection & $8(32.00)$ & & \\
\hline
\end{tabular}

anesthesia group (group I, $n=25$ ), the epidural anesthesia group (group II, $\mathrm{n}=25$ ) and the general anesthesia group (group III, n=25). All patients underwent electrocardiogram, echocardiography, blood gas analysis, cardiac function measurement and other examinations and tests, and they met the diagnostic criteria related to severe $\mathrm{PAH}$; it was detected via echocardiography that the systolic blood pressure of pulmonary artery was $\geq 70 \mathrm{mmHg}$. The patients did not take drugs containing sex hormones within 2 months. There were no significant differences in the clinical basic data among the three groups of patients $(\mathrm{P}>0.05)$ (Table I). Signed informed consent was obtained from all the patients and their families. This study was approved by the Ethics Committee of Jining First People's Hospital.

Research methods. The patients were given oxygen inhalation and intravenous infusion before the operation to maintain stable vital signs. In the perioperative period, vasoactive substances were used routinely to the patients to adjust the blood pressure, and antibiotics were applied to prevent infections.

\section{Observation indexes}

Monitoring of hemodynamic indexes at different time-points. Finometer ${ }^{\circledR}$ PRO non-invasive hemodynamics monitor (Finapres Medical Systems B.V., Amsterdam, The Netherlands) was used to record the values of systolic blood pressure, diastolic blood pressure and blood oxygen saturation in the three groups at $\mathrm{T}_{0}$ (before anesthesia), $\mathrm{T}_{1}$ (after fetal birth) and $\mathrm{T}_{2}$ (at the end of the operation), of which the index difference $\Delta=\mathrm{T}_{1}-\mathrm{T}_{0}$ or $\mathrm{T}_{2}-\mathrm{T}_{0}$.

Observation of pregnancy outcomes of the three groups of patients. The time period of recording puerpera's death was from the start of the pregnancy to 42 days after the childbirth; the time period of recording the neonate's death was from the delivery to 28 days later; the neonatal asphyxia standard was based on the Apgar score, and it was determined that the Apgar score $<7$ points at $1 \mathrm{~min}$ indicated neonatal asphyxia, of which 0-3 points represented for severe, and 4-7 points for mild.

Observation of postoperative situations in the three groups. Days of intensive care unit (ICU) stay of the puerpera after the operation, days of ventilator support ventilation through continuous trachea intubation of the puerpera after the operation and days from the end of the operation to discharge from hospital of the puerpera after the operation.

Detection of changes in hormone levels at different time-points in the three groups. Cobas e601 automatic electrochemiluminescence immunoassay analyzer (Roche, Basel, Switzerland) was used for electrochemiluminescence to detect the concentrations of plasma total testosterone (TT), estradiol (E2), follicle stimulating hormone (FSH), luteinizing hormone ( $\mathrm{LH}$ ), progestogen (PROG), human chorionic gonadotrophin (HCG) and prolactin (PRL) before the operation and at 24, 48 and $72 \mathrm{~h}$ after the operation.

Statistical analysis. The data were entered into the SPSS 19.0 (SPSS, Inc., Chicago, IL, USA) for statistical analysis; the measurement data were presented as mean \pm standard deviation (SD) and t-test was applied. The enumeration data were presented as n (\%), and Chi-square test or Fisher's exact test were used for inspections. $\mathrm{P}<0.05$ was considered to indicate a statistically significant difference.

\section{Results}

Comparisons of general conditions. There were no statistically significant differences in age, weight, pregnancy-labor history, gestational age, complications, cardiac disease history, cardiac function and other general information among the three groups $(\mathrm{P}>0.05)$ (Table I). 
Table II. Comparisons of hemodynamic changes at different time-points among the three groups of patients ( $\mathrm{n}=25$ ).

\begin{tabular}{|c|c|c|c|c|c|c|}
\hline Groups & $\begin{array}{l}\text { Systolic blood } \\
\text { pressure }\end{array}$ & $\begin{array}{c}\Delta \text { Systolic } \\
\text { blood pressure }\end{array}$ & $\begin{array}{c}\text { Diastolic blood } \\
\text { pressure }\end{array}$ & $\begin{array}{c}\Delta \text { Diastolic } \\
\text { blood pressure }\end{array}$ & $\begin{array}{l}\text { Blood oxygen } \\
\text { saturation }\end{array}$ & $\begin{array}{c}\Delta \text { Blood oxygen } \\
\text { saturation }\end{array}$ \\
\hline \multicolumn{7}{|l|}{ T0 } \\
\hline I & $154.22 \pm 15.32$ & & $90.12 \pm 6.38$ & & $90.02 \pm 6.98$ & \\
\hline II & $151.45 \pm 16.52$ & & $89.91 \pm 6.65$ & & $89.98 \pm 5.83$ & \\
\hline III & $156.70 \pm 15.88$ & & $88.00 \pm 8.02$ & & $89.02 \pm 6.78$ & \\
\hline \multicolumn{7}{|l|}{$\mathrm{T} 1$} \\
\hline I & $136.70 \pm 8.97^{\mathrm{a}}$ & $16.41 \pm 6.65^{\mathrm{b}, \mathrm{c}}$ & $84.91 \pm 4.10^{\mathrm{a}}$ & $4.28 \pm 1.39^{\mathrm{b}, \mathrm{c}}$ & $91.88 \pm 3.43^{\mathrm{a}}$ & $3.22 \pm 1.73^{b}$ \\
\hline II & $131.12 \pm 8.28^{\mathrm{a}}$ & $21.79 \pm 7.01^{\mathrm{b}}$ & $81.77 \pm 4.98^{a}$ & $7.02 \pm 2.03^{\mathrm{b}}$ & $92.25 \pm 3.93^{\mathrm{a}}$ & $3.03 \pm 1.92^{\mathrm{b}}$ \\
\hline III & $123.68 \pm 9.10^{\mathrm{a}}$ & $31.35 \pm 5.61$ & $77.33 \pm 5.05^{\mathrm{a}}$ & $7.98 \pm 3.05$ & $95.22 \pm 4.11^{\mathrm{a}}$ & $8.02 \pm 1.98$ \\
\hline \multicolumn{7}{|l|}{$\mathrm{T} 2$} \\
\hline I & $127.72 \pm 7.18^{\mathrm{a}}$ & $28.03 \pm 5.00^{\mathrm{b}, \mathrm{c}}$ & $79.19 \pm 6.52^{\mathrm{a}}$ & $8.79 \pm 2.88^{b, c}$ & $93.92 \pm 3.48^{\mathrm{a}}$ & $5.04 \pm 2.22^{b}$ \\
\hline II & $119.88 \pm 8.05^{\mathrm{a}}$ & $31.49 \pm 4.98^{\mathrm{b}}$ & $76.48 \pm 4.50^{\mathrm{a}}$ & $11.77 \pm 1.28^{\mathrm{b}}$ & $94.77 \pm 2.56^{\mathrm{a}}$ & $5.62 \pm 3.10^{b}$ \\
\hline III & $113.12 \pm 12.33^{\mathrm{a}}$ & $43.35 \pm 6.77$ & $73.15 \pm 4.98^{a}$ & $13.88 \pm 2.70$ & $97.12 \pm 4.48^{\mathrm{a}}$ & $9.78 \pm 2.68$ \\
\hline
\end{tabular}

${ }^{\mathrm{a}}$ Comparison with that at T0; ${ }^{\mathrm{b}}$ comparison with that in group III; ${ }^{\mathrm{c}}$ comparison with that in group II; $\mathrm{P}<0.05$ suggests that the difference is statistically significant.

Table III. Comparison of hospitalization after the operation among the three groups of pregnant patients (mean $\pm \mathrm{SD}$ ).

\begin{tabular}{lcccc}
\hline Groups & No. & $\begin{array}{c}\text { Postoperative } \\
\text { hospital stay }\end{array}$ & $\begin{array}{c}\text { ICU } \\
\text { staying time }\end{array}$ & $\begin{array}{c}\text { Time of } \\
\text { mechanical } \\
\text { ventilation }\end{array}$ \\
\hline I & 25 & $8.16 \pm 2.53^{\mathrm{a}}$ & $3.35 \pm 2.10^{\mathrm{a}}$ & $2.01 \pm 1.16^{\mathrm{a}}$ \\
II & 25 & $8.77 \pm 2.28^{\mathrm{a}}$ & $4.01 \pm 1.78^{\mathrm{a}}$ & $2.15 \pm 1.38^{\mathrm{a}}$ \\
III & 25 & $15.88 \pm 9.45$ & $7.99 \pm 5.87$ & $5.66 \pm 4.23$ \\
\hline
\end{tabular}

${ }^{\mathrm{a}} \mathrm{P}<0.05$ compared with group III.

Comparisons of hemodynamic changes at different time-points among the three groups. At T1 and T2, the hemodynamic levels in the three groups were statistically different from those at T0 $(\mathrm{P}<0.05)$; the systolic and diastolic blood pressure in groups I and II were higher than those in group III, and the $\Delta$ changes in the two groups were obviously smaller than that in group III $(\mathrm{P}<0.05)$. At $\mathrm{T} 1$ and $\mathrm{T} 2$, the levels of blood oxygen saturation in groups I and II were lower than those in group III, and the $\Delta$ changes in the two groups were notably smaller than that in group III $(\mathrm{P}<0.05)$ (Table II).

Comparison of hospitalization after the operation among the three groups. The postoperative hospital stay, staying time in ICU and time of mechanical ventilation of the pregnant patients in groups I and II were obviously shorter than those in group III $(\mathrm{P}<0.05)$; the differences between groups I and II were not statistically significant $(\mathrm{P}>0.05)$ (Table III).

Comparisons of pregnancy outcomes among the three groups. The results of neonatal mortality rate, neonatal asphyxia rate and maternal mortality rate in the three groups showed
Table IV. Comparisons of pregnancy outcomes among the three groups of pregnant patients, $\mathrm{n}(\%)$.

\begin{tabular}{lcccc}
\hline Groups & No. & $\begin{array}{c}\text { Neonatal } \\
\text { death }\end{array}$ & $\begin{array}{c}\text { Neonatal } \\
\text { asphyxia }\end{array}$ & $\begin{array}{c}\text { Maternal } \\
\text { death }\end{array}$ \\
\hline I & 25 & $1(4.0)$ & $3(12.0)$ & $0(0.0)$ \\
II & 25 & $0(0.0)$ & $3(12.0)$ & $1(4.0)$ \\
III & 25 & $0(0.0)$ & $4(16.0)$ & $1(4.0)$ \\
\hline
\end{tabular}

that the indexes in group I were 4.0, 12.0 and $0.0 \%$, respectively; the neonatal mortality rate, neonatal asphyxia rate and maternal mortality rate in group II were $0.0,12.0$ and $4.0 \%$, respectively, and those in group II were $0.0,16.0$ and $4.0 \%$, respectively. There were no statistically significant differences in comparison between the groups ( $\mathrm{P}>0.05)$ (Table IV).

Changes in sex hormone levels in each group at different time-points. The levels of E2, HCG and TT in the three groups of patients at each time-point after the operation were decreased significantly compared with those before the operation, while the levels FSH, LH and PROG were increased to some extent after the operation, of which the differences in the decreasing degrees of E2 and TT at each time-point were statistically significant $(\mathrm{P}<0.05)$. Moreover, the $\mathrm{E} 2$ level in group III at each time-point was lower than those in groups II and I, and at $72 \mathrm{~h}$ after the operation, the difference in comparison between the groups was statistically significant. The PROG level in group III at each time-point was elevated compared with those in groups I and II, but there was no statistically significant difference $(\mathrm{P}>0.05)$ (Table $\mathrm{V})$.

Correlation analysis results of sex hormones and blood pressure. With the concentrations of TT, E2, LH, FSH, PROG, 


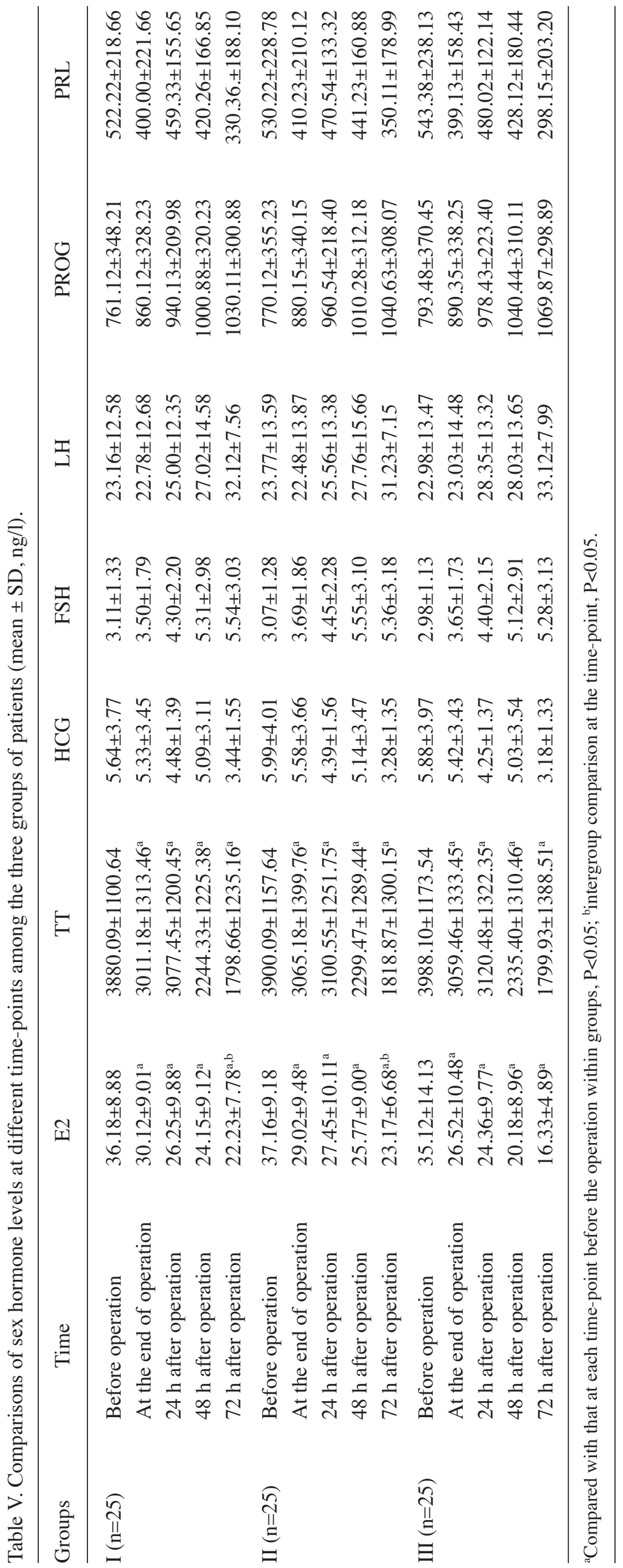


Table VI. Correlation analysis of serum inflammatory factors and pulmonary functions in case of pregnancy complicated with severe PAH (r value).

\begin{tabular}{lccccrrr}
\hline Relevant variable & TT & E2 & HCG & PRL & FSH & LH & PROG \\
\hline Systolic blood pressure & $-1.010^{\mathrm{a}}$ & $-0.792^{\mathrm{a}}$ & -0.170 & -0.313 & -0.412 & -0.312 \\
Diastolic blood pressure & $-0.811^{\mathrm{a}}$ & $-0.688^{\mathrm{a}}$ & -0.179 & -0.289 & -0.403 & -0.303 & -0.189 \\
\hline
\end{tabular}

TT, total testosterone; E2, estradiol; FSH, follicle stimulating hormone; LH, luteinizing hormone; PROG, progestogen; HCG, human chorionic gonadotrophin; PRL, prolactin. ${ }^{\text {a }}$ Significant correlationship.

PRL and HCG as the independent variables and with systolic blood pressure and diastolic blood pressure as the dependent variables, the analysis results indicated that the contents of E2 and TT were directly correlated with blood pressure, and the difference was statistically significant $(\mathrm{P}<0.05)$ (Table VI).

\section{Discussion}

The increase in cardiac output and decrease in resistance of all blood vessels (including pulmonary vessels) at the same time in the normal pregnant women can maintain the mean pulmonary artery pressure (mPAP) during pregnancy at the level before the pregnancy (5). However, for pregnant patients complicated with PAH, the sharp changes in blood volume during labor and after childbirth, as well as decreased in vena cava pressure may induce right heart failure; therefore, in most cases, caesarean section is conducted to terminate pregnancy in intermediate and advanced stage (6-8). Intravertebral anesthesia is the best way to terminate pregnancy for pregnant women complicated with PAH, which includes combined spinal/epidural anesthesia and epidural anesthesia (9). Intravertebral anesthesia can effectively decrease the peripheral vascular resistance (PVR) and reduce returned blood volume, thus lowering the myocardial oxygen consumption; during the anesthesia process, trachea intubation is not needed, so that the interference of mechanical ventilation in blood circulation can be avoided, and the risk of pulmonary infection is reduced. General anesthesia decreases the occurrence of acute pulmonary edema in the patients through the analgesia, sedation and muscle relaxation effects; the application of ventilator support improves the oxygen supply to the patients, but it increases the risk of pulmonary infection at the same time; drugs have different degrees of inhibition on the patients' cardiac functions $(10,11)$.

The results of the present study showed that, whether intravertebral anesthesia (including epidural anesthesia and combined spinal/epidural anesthesia) or general anesthesia was adopted, the systolic blood pressure and diastolic blood pressure after anesthesia were decreased remarkably compared with those before anesthesia $(\mathrm{P}<0.05)$. The changes in systolic blood pressure and diastolic blood pressure of the pregnant patients in groups II and I were obviously smaller than those in group III $(\mathrm{P}<0.05)$, indicating that intravertebral anesthesia has milder impacts on the hemodynamics, which can effectively avoid rapid drop in blood pressure of the pregnant patients caused by fetal birth during caesarean section. The analysis on the outcomes of the three groups of patients found that there were no statistically significant differences in neonatal mortality rate, neonatal asphyxia rate and maternal mortality rate $(\mathrm{P}<0.05)$. The time of postoperative hospital stay, ICU stay and mechanical ventilation time in groups II and I were obviously shorter than those in group III, and the differences were statistically significant $(\mathrm{P}<0.05)$.

In normal puerperae, the sex hormone levels are elevated rapidly after pregnancy; after labor, the levels of estrogen and so on are lowered greatly and returned gradually to normal at 6 weeks after labor; during the whole pregnancy and labor, E2, FSH, LH, PG, PRL, TT, HCG and other sex hormones play complex regulatory roles in pregnancy (12). The impact of sex hormone changes during pregnancy on PAH has not been elaborated completely. The latest research results have revealed that E2 and testosterone can suppress the endothelin activity by improving the activities of endothelial nitric oxide (NO) synthase and prostacyclin synthase, thus inhibiting the pulmonary vasoconstriction $(13,14)$. It was found through estrogen replacement treatment test that the ejection fraction of the right ventricular (RV) is related to E2 level (9), and E2 is beneficial to RV functions of PAH patients during pregnancy, that is, the processes mediated by $\mathrm{E} 2$ receptor, which are good for myocardial metabolism, inflammation, fibration, stromal remodeling and cell apoptosis, have a correlation with its effect of improving cardiac function and mortality rate (15-17). It was reported in literature that the decrease in PVR may be associated with the mediation of sex hormones (18); studies have indicated that the 'withdrawal phenomenon' of estrogen, after labor may lead to pulmonary vasoconstriction (6). In this experiment, the hormone levels of the patients at different time-points of perioperative period were measured, and it was discovered that the levels of E2, HCG and TT in the three groups of patients at each time-point after the operation were decreased significantly compared with those before the operation, while the levels FSH, LH and PROG were increased to some extent after the operation, of which the differences in the decreasing degrees of E2 and TT at each time-point were statistically significant $(\mathrm{P}<0.05)$. Moreover, the E2 level in group III at each time-point was lower than those in groups II and I, and at $72 \mathrm{~h}$ after the operation, the difference in comparison between the groups was statistically significant. In combination with the hemodynamics examination results, the changes in systolic blood pressure and diastolic blood pressure of the pregnant patients in groups II and I were obviously smaller than those in group III. Further statistical analysis revealed that the contents of sex hormones E2 and TT were directly related to arterial blood pressure, indicating that the decrease 
in E2 and TT may be one of the reasons for greater fluctuations in postoperative hemodynamics in group III than those in the other two groups; timely utilization of estrogen replacement therapy can ameliorate the patients' conditions.

In conclusion, for pregnant patients complicated with severe PAH, there is no significant difference in pregnancy outcomes among the three anesthesia methods, but the changes in hemodynamics of patients in epidural anesthesia group and combined spinal/epidural anesthesia group are more stable; meanwhile, the mechanical ventilation time, ICU stay and postoperative hospital stay are shortened remarkably; therefore, intravertebral anesthesia is preferred in case of patients without contraindication of the anesthesia.

\section{Acknowledgements}

Not applicable.

\section{Funding}

No funding was received.

\section{Availability of data and materials}

All data generated or analyzed during this study are included in this published article.

\section{Authors' contributions}

YW and HX designed the study and performed the follow-up, HL and YL collected the data, YW and QB analysed the data, YW and YL prepared the manuscript. All authors read and approved the final manuscript.

\section{Ethics approval and consent to participate}

This study was approved by the Ethics Committee of Jining First People's Hospital (Jining, China). Signed written informed consents were obtained from the patients and/or guardians.

\section{Consent for publication}

Not applicable.

\section{Competing interests}

The authors declare that they have no competing interests.

\section{References}

1. Bhatia R, Kaeley N and Bhatia R: Anaesthetic management of caesarean section in a term pregnancy with ventricular septal defect and pulmonary hypertension with severe pulmonary stenosis. J Clin Diagn Res 10: UD03-UD04, 2016.

2. Galiè N, Humbert M, Vachiery JL, Gibbs S, Lang I, Torbicki A, Simonneau G, Peacock A, Vonk Noordegraaf A, Beghetti M, et al 2015 ESC/ERS guidelines for the diagnosis and treatment of pulmonary hypertension: The joint task force for the diagnosis and treatment of pulmonary hypertension of the european society of cardiology (ESC) and the european respiratory society (ERS) Endorsed by: Association for european paediatric and congenital cardiology (AEPC), international society for heart and lung transplantation (ISHLT). Eur Heart J 37: 67-119, 2016.
3. Sharma K, Afshar YR, Bairey-Merz CN, Tapson V, Zakowski M and Kilpatrick SJ: Guidelines and consensus: Statement on pregnancy in pulmonary hypertension from the Pulmonary Vascular Research Institute. Pulm Circ 6: 143, 2016.

4. Li WJ, Hu K, Yang JP, Xu XY, Li N, Wen ZP and Wang H: HMGB1 affects the development of pulmonary arterial hypertension via RAGE. Eur Rev Med Pharmacol Sci 21: 3950-3958, 2017.

5. Roche-Kelly E and Nelson-Piercy C: Managing cardiovascular disease during pregnancy: Best practice to optimize outcomes. Future Cardiol 10: 421-433, 2014.

6. Hemnes AR, Kiely DG, Cockrill BA, Safdar Z, Wilson VJ, Al Hazmi M, Preston IR, MacLean MR and Lahm T: Statement on pregnancy in pulmonary hypertension from the Pulmonary Vascular Research Institute. Pulm Circ 5: 435-465, 2015.

7. Gei A and Montúfar-Rueda C: Pulmonary hypertension and pregnancy: An overview. Clin Obstet Gynecol 57: 806-826, 2014.

8. Kiely DG, Condliffe R, Wilson VJ, Gandhi SV and Elliot CA: Pregnancy and pulmonary hypertension: A practical approach to management. Obstet Med 6: 144-154, 2013.

9. Ventetuolo CE, Praestgaard A, Palevsky HI, Klinger JR, Halpern SD and Kawut SM: Sex and haemodynamics in pulmonary arterial hypertension. Eur Respir J 43: 523-530, 2014.

10. Idehen HO, Amadasun FE and Ekwere IT: Comparison of intravenous colloid and colloid-crystalloid combination in hypotension prophylaxis during spinal anesthesia for cesarean section. Niger J Clin Pract 17: 309-313, 2014.

11. Behdad S, Hajiesmaeili MR, Abbasi HR, Ayatollahi V, Khadiv Z and Sedaghat A: Analgesic effects of intravenous ketamine during spinal anesthesia in pregnant women undergone caesarean section; A randomized clinical trial. Anesth Pain Med 3: 230-233, 2013.

12. Oshima T, Nakajima S, Yokoyama T, Toyoshima F, Sakurai J, Tanaka J, Tomita T, Kim Y, Hori K, Matsumoto T, et al: The G-protein beta3 subunit 825 TT genotype is associated with epigastric pain syndrome-like dyspepsia. BMC Med Genet 11: $13,2010$.

13. Duarte AG, Thomas S, Safdar Z, Torres F, Pacheco LD, Feldman $\mathrm{J}$ and deBoisblanc B: Management of pulmonary arterial hypertension during pregnancy: A retrospective, multicenter experience. Chest 143: 1330-1336, 2013.

14. Tofovic SP: Estrogens and development of pulmonary hypertension: Interaction of estradiol metabolism and pulmonary vascular disease. J Cardiovasc Pharmacol 56: 696-708, 2010.

15. Queirós AM, Eschen C, Fliegner D, Kararigas G, Dworatzek E, Westphal C, Sanchez Ruderisch H and Regitz-Zagrosek V: Sexand estrogen-dependent regulation of a miRNA network in the healthy and hypertrophied heart. Int J Cardiol 169: 331-338, 2013.

16. Kararigas G, Fliegner D, Gustafsson JA and Regitz-Zagrosek V: Role of the estrogen/estrogen-receptor-beta axis in the genomic response to pressure overload-induced hypertrophy. Physiol Genomics 43: 438-446, 2011.

17. Dumas de La Roque E, Bellance N, Rossignol R, Begueret H, Billaud M, dos Santos P, Ducret T, Marthan R, Dahan D, Ramos-Barbón D, et al: Dehydroepiandrosterone reverses chronic hypoxia/reoxygenation-induced right ventricular dysfunction in rats. Eur Respir J 40: 1420-1429, 2012.

18. Yuan P, Wu WH, Gao L, Zheng ZQ, Liu D, Mei HY, Zhang ZL and Jing ZC: Oestradiol ameliorates monocrotaline pulmonary hypertension via NO, prostacyclin and endothelin-1 pathways. Eur Respir J 41: 1116-1125, 2013.

This work is licensed under a Creative Commons Attribution-NonCommercial-NoDerivatives 4.0 International (CC BY-NC-ND 4.0) License. 